\title{
Histopathology of Giant Coronary Artery Aneurysm Associated with Coronary Artery Fistula A Case Report
}

\author{
Yuji Matsumoto, ${ }^{1} \mathrm{MD}$, Hiroaki Kawano, ${ }^{2} \mathrm{MD}$, Keisuke Iwasaki, ${ }^{3} \mathrm{MD}$, \\ Shuji Arakawa, ${ }^{2}$ MD and Koji Maemura, ${ }^{2}$ MD
}

\begin{abstract}
Summary
Giant coronary artery aneurysms related to coronary fistula are rare, and the precise mechanisms by which they occur are unknown. We present a case of giant coronary artery aneurysm of the left coronary artery to the pulmonary artery fistula with a lack of internal and (or) external elastic lamina and medial degeneration.
\end{abstract}

(Int Heart J 2018; 59: 431-434)

Key words: Medial mucoid degeneration, Pathology

$\mathrm{C}$ oronary artery fistula (CAF) is a rare abnormal connection between a coronary artery and another coronary artery, major vessel, or cardiac chamber, ${ }^{1)}$ and multiple coronary micro fistulae have also been reported. ${ }^{2)}$ The prevalence of CAF is reportedly $0.2 \%$ to $2 \%$ in patients who undergo coronary angiography. ${ }^{3,4)} \mathrm{Po}-$ tential long-term complications caused by a large left-toright shunt include right ventricular enlargement, pulmonary hypertension, congestive heart failure, and rupture or thrombosis of the fistula or associated arterial aneurysm. ${ }^{5)}$

Coronary artery aneurysm is seen in $0.3 \%$ to $5 \%$ of patients undergoing coronary angiography, and the prevalence of giant coronary artery aneurysms (defined as having a diameter $\geq 2 \mathrm{~cm}$ ) is reportedly $0.02-0.2 \%$. $^{6}$ Thus, giant coronary aneurysms associated with coronary fistulae are very rare, and their precise mechanism of formation is unknown. We present a case of a giant coronary artery aneurysm of fistula from the left coronary artery to the pulmonary artery with precise histological examination, and we also review previous reports of giant coronary artery aneurysm associated with coronary fistula.

\section{Case Report}

A 68-year-old asymptomatic Japanese woman was referred to our hospital for evaluation of an abnormal shadow that was detected on routine chest X-ray performed at her medical check-up. She had hypertension and was treated with $5 \mathrm{mg}$ amlodipine once a day. Her past medical and surgical history was also notable for onset of hypothyroidism at 64 years and cholecystectomy due to gallstones at 67 years. She had no other diseases such as Kawasaki, inflammatory, or connective tissue dis- ease.

Physical examination on admission revealed a blood pressure of $126 / 68 \mathrm{mmHg}$, a heart rate of $70 \mathrm{bpm}$, and a body temperature was $36.5^{\circ} \mathrm{C}$. A continuous Levine grade II heart murmur was heard at the second intercostal space of the left sternal border.

Laboratory testing showed a white blood cell count of $5,140 / \mathrm{mm}^{3}$, hemoglobin of $13.4 \mathrm{~g} / \mathrm{dL}$, blood urea nitrogen of $13.2 \mathrm{mg} / \mathrm{dL}$, creatinine of $0.70 \mathrm{mg} / \mathrm{dL}$, aspartate aminotransferase of $26 \mathrm{IU} / \mathrm{L}$, alanine aminotransferase of $33 \mathrm{IU} / \mathrm{L}$, lactate dehydrogenase of $216 \mathrm{IU} / \mathrm{L}$, creatine kinase of $117 \mathrm{IU} / \mathrm{L}, \mathrm{C}$-reactive protein of $0.06 \mathrm{mg} / \mathrm{dL}$, and brain natriuretic peptide of $21.1 \mathrm{pg} / \mathrm{mL}$.

A chest X-ray showed a bulge in the third arch of the left heart border that was not present on a comparison X-ray taken 7 years prior (Figure 1A, B). The electrocardiogram was almost normal and the transthoracic echocardiography was normal with a left ventricular ejection fraction of $73 \%$. Three-dimensional coronary artery computed tomography (Figure 1C) and a coronary angiography (Figure 1D) showed a giant aneurysm (3 $\mathrm{cm}$ in diameter) of the left anterior descending artery segment 6 in the left coronary artery to main pulmonary artery fistula. Cardiac catheterization revealed that the left-to-right shunt was very small $(\mathrm{Qp} / \mathrm{Qs}=1.02: 1)$. Exercise stress thallium-201 single-photon emission computed tomography myocardial perfusion imaging showed no myocardial ischemia.

After the diagnosis, surgery was recommended due to the risk of rupture. The aneurysmal wall was resected and closed after the openings of the three vessels to the aneurysm were closed with sutures.

The resected aneurysm contained a fistula conduit from the left anterior descending (LAD) of the left coro-

From the ${ }^{1}$ Department of Cardiology, Sasebo Municipal General Hospital, Sasebo, Japan, ${ }^{2}$ Department of Cardiovascular Medicine, Nagasaki University Graduate School of Biomedical Sciences, Nagasaki, Japan and ${ }^{3}$ Department of Pathology, Sasebo Municipal General Hospital, Sasebo, Japan.

Address for correspondence: Hiroaki Kawano, MD, Department of Cardiovascular Medicine, Nagasaki University Graduate School of Biomedical Sciences,

1-7-1 Sakamoto, Nagasaki, Nagasaki 852-8501 Japan. E-mail: hkawano@nagasaki-u.ac.jp

Received for publication February 22, 2017. Revised and accepted May 1, 2017.

Released in advance online on J-STAGE February 23, 2018.

doi: 10.1536/ihj.17-103

All rights reserved by the International Heart Journal Association. 

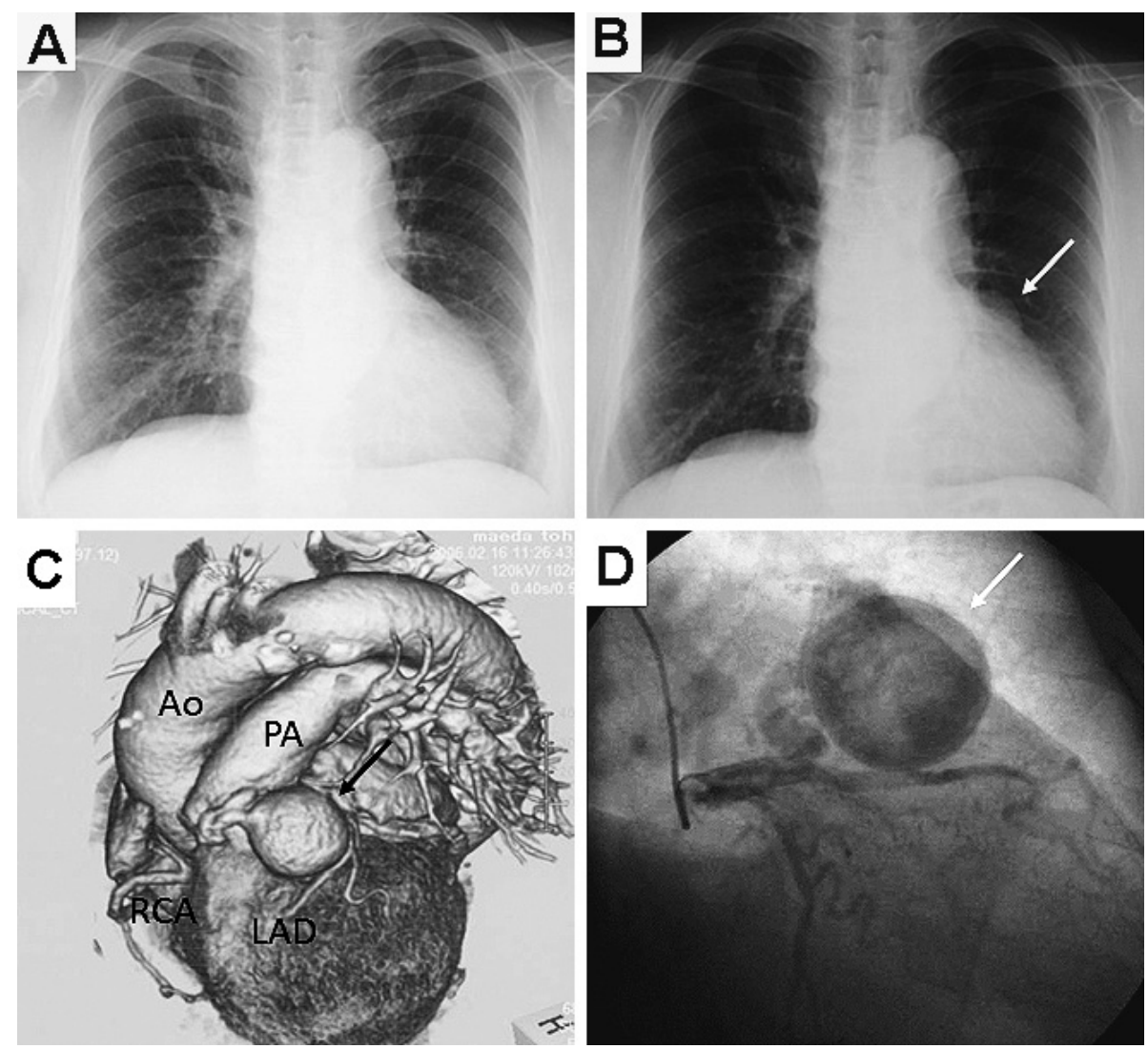

Figure 1. Chest $\mathrm{X}$-ray shows a bulge in the third arch of the left heart border (B, arrow), although there was no observable mass on the chest X-ray taken 7 years before (A). Three-dimensional coronary artery computed tomography $(\mathbf{C})$ and coronary angiogram (D) show the giant aneurysm (3 $\mathrm{cm}$ in diameter) (arrow) of the left anterior descending artery segment 6 in the left coronary artery to the main pulmonary artery fistula. Ao, aorta; PA, pulmonary artery; LV, left ventricle; RCA, right coronary artery; and LCA, left coronary artery.

nary artery.

Histological examination of the aneurysm showed that in the fistula conduit from the LAD, the wall consisted of almost normal arterial structure containing intima, internal elastic lamina, media, external elastic lamina, and adventitia with mild intimal thickening and mild atherosclerotic change (Figure 2A, B, C). However, the wall of the aneurysm had a gradual decrease of smooth muscle cells in the media (Figure 2D, E) with a lack of external elastic lamina from the entry of the fistula conduit from the LAD to the distal site of the aneurysmal wall (Figure 2E), and in aneurysmal wall at about $15 \mathrm{~mm}$ from the entry of the fistula conduit from the LAD (Figure $2 \mathrm{D}, \mathrm{E})$, the media and internal elastic lamina almost disappeared and changed to fibrosis without inflammatory cells (Figure 2D, E). Moreover, the remaining aneurysmal wall had been almost completely transformed by fibrosis in the media, in addition to disrupted external elastic lamina with intimal thickening (Figure 2G, H). Deposition of Alcian blue-positive materials was also strongly observed in the aneurysmal wall (Figure $2 \mathrm{~F}, \mathrm{I}$ ), although there was mild deposition of Alcian blue-positive materials in the media of the fistula conduit (Figure 2C).

\section{Discussion}

The most common cause of coronary aneurysms is atherosclerosis, and non-atherosclerotic causes of giant coronary artery aneurysm include connective tissue disorders, vasculitis, infections, drug abuse, and trauma. ${ }^{7)}$ However, the precise mechanism of giant coronary aneurysm associated with coronary artery fistula (CAF) is not known.

We conducted a literature search for reports of giant coronary artery aneurysm associated with coronary fistula and investigated case backgrounds using the term "coronary aneurysm" and "coronary fistula" in PubMed until February 2017.

There have been 12 previous case reports of histological changes of giant coronary artery aneurysm (defined as diameter $\geq 2 \mathrm{~cm}$ ) associated with coronary fistula (Table). ${ }^{4,-18)}$ Among those reported cases and the present case (age range, 38 to 79 years; mean age, $64 \pm 13$ years; four men and nine women; maximum diameter of aneurysm, 33 to $100 \mathrm{~mm}$, and mean diameter, $60 \pm 19 \mathrm{~mm}$ ), the aneurysms were located in the LAD of the left coronary artery in seven patients, in the circumflex of the left coronary artery in two patients, and in the right coronary 

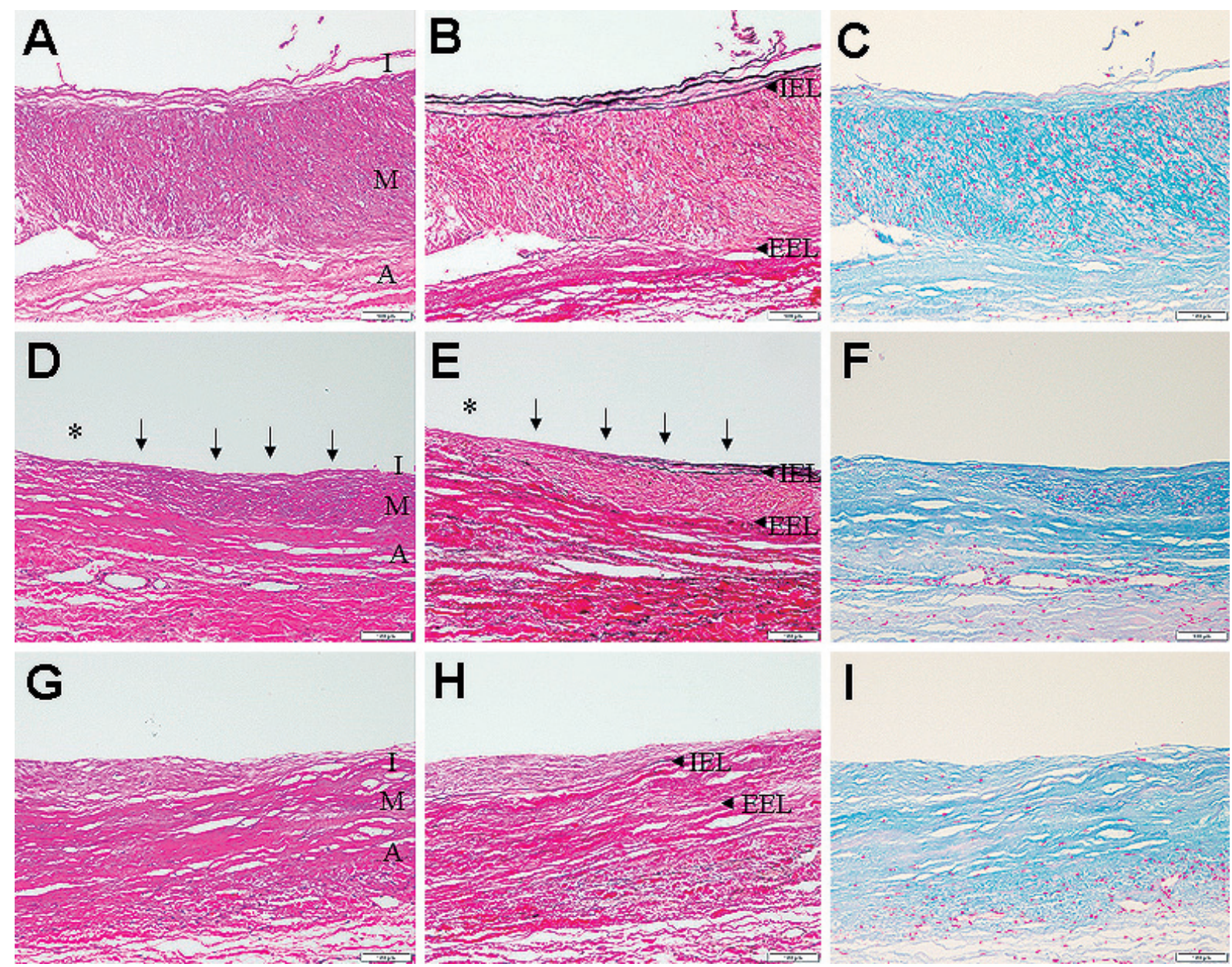

Figure 2. In the fistula conduit from the LAD, the wall consisted of almost normal arterial structure containing intima (I), internal elastic lamina (IEL), media (M), external elastic lamina (EEL), and adventitia (A) with mild intimal thickening (A, B) and mild degeneration and deposition of Alcian blue-positive materials in the media (C). However, the wall of the aneurysm had a gradual decrease of smooth muscle cells in the media (D, E; arrows) with a lack of EEL from the entry of the fistula conduit from the LAD to the distal site (E; arrow head of EEL), and about $15 \mathrm{~mm}$ from the entry of the fistula conduit from the LAD $(\mathbf{D}, \mathbf{E} ; *)$, the media and IEL disappeared and changed to fibrosis without inflammatory cells (D, E). Moreover, the remaining of the aneurysmal wall had been almost completely transformed by fibrosis, in addition to disrupted EEL with preserved internal elastic lamina (IEL) $(\mathbf{G}, \mathbf{H})$. Deposition of Alcian blue-positive materials was also seen in the aneurysmal wall $(\mathbf{F}, \mathbf{I})$. A, D, and G; Hematoxylin-eosin staining: B, E, and $\mathbf{H}$; Elastica van Gieson staining: C, F, and $\mathbf{I}$; Alcian blue staining: bar is $100 \mu \mathrm{m}$.

Table. Histological Findings of Giant Coronary Artery with Coronary Fistula in Previous Reports and Our Report

\begin{tabular}{|c|c|c|c|c|c|c|c|c|}
\hline Case & $\begin{array}{c}\text { Age } \\
\text { (years) }\end{array}$ & Sex & Aneurysm site & Drain site & Size (mm) & Histological findings & Rupture & Ref \\
\hline 1 & 69 & $\mathrm{~F}$ & LAD & PA & $30 \times 40$ & atherosclerosis & $(+)$ & 3 \\
\hline 2 & 58 & M & LCX & $\mathrm{CS}$ & $70 \times 60$ & atherosclerosis & $(-)$ & 8 \\
\hline 3 & 76 & $\mathrm{~F}$ & LAD & PA & $50 \times 50$ & atherosclerosis & $(+)$ & 9 \\
\hline 4 & 77 & $\mathrm{~F}$ & RCA & $\mathrm{CS}$ & $80 \times 70 \times 80$ & atherosclerosis & $(-)$ & 11 \\
\hline 5 & 76 & $\mathrm{~F}$ & RCA & LA & $70 \times 50$ & atherosclerosis & $(-)$ & 12 \\
\hline 6 & 65 & $\mathrm{~F}$ & LAD & $\mathrm{PA}$ & $52 \times 62$ & atherosclerosis & $(-)$ & 14 \\
\hline 7 & 52 & M & RCA & RA & 48 & mucoid degeneration & $(-)$ & 10 \\
\hline 8 & 79 & $\mathrm{~F}$ & LAD & PA & $45 \times 46$ & mucoid degeneration and inflammatory cells & $(-)$ & 13 \\
\hline 9 & 51 & $\mathrm{~F}$ & LCX & RA & $100 \times 80$ & cystic medial change & $(-)$ & 16 \\
\hline 10 & 75 & $\mathrm{~F}$ & RCA & LV & 33 & cystic medial degeneration and mild atherosclerosis & $(-)$ & 17 \\
\hline 11 & 54 & M & LAD & LV & 80 & dysplastic medial change & $(-)$ & 7 \\
\hline 12 & 38 & M & LAD & RCA & $40 \times 35$ & degenerative change, fatty infiltration, calcification & $(-)$ & 15 \\
\hline 13 & 68 & $\mathrm{~F}$ & LAD & PA & $30 \times 30$ & disappearance and degeneration of media & $(-)$ & this case \\
\hline
\end{tabular}

$\mathrm{M}$ indicates male; F, female; LCX, the circumflex of the left coronary artery; LAD, the left anterior descending of the left coronary artery; RCA, the right coronary artery; CS, coronary sinus; PA, pulmonary artery; LA, left atrium; RA, right atrium; and LV, left ventricle. 
artery (RCA) in four patients. Further, there was LAD to pulmonary artery fistula in five patients, LAD to the left ventricle fistula in one patient, LAD to the RCA fistula in one patient, RCA to the right atrium fistula in one patient, RCA to the left atrium fistula in one patient, RCA to the left ventricle fistula in one patient, RCA to the coronary sinus fistula in one patient, RCA to the right atrium fistula in one patient, and LCX to the coronary sinus fistula in one patient.

The histological changes were as follows: atherosclerosis in six patients, mucoid degeneration in three patients (one case with infiltration of inflammatory cells), both atherosclerosis and mucoid degeneration in one patient, dysplastic medial change in one patient, and degenerative change with fatty infiltration and calcification in one patient. There was no difference in the incidence of histological changes among different coronary arteries or fistula-draining sites. Two of these reported 12 patients had aneurysm rupture, and both cases were related to atherosclerosis.

In the present patient, a lack of internal and (or) external elastic lamina and the presence of medial degeneration including decreased or disappeared smooth muscle cells, replacement fibrosis, and mucoid deposition were observed. These histological findings have not been reported in patients with giant coronary artery aneurysm associated with coronary fistula. However, Sakata, et al. ${ }^{19)}$ suggested that a structural change of the CAF such as disrupted internal elastic lamina and phenotypic changes of the medial smooth muscle cells might contribute to aneurysmal formation (7-8 $\mathrm{mm}$ in diameter) in a patient with coronary-pulmonary arterial fistula. Thus, wall weakness related to medial degeneration in addition to a lack of internal and (or) external elastic lamina of the CAF conduit may have contributed to the development of the giant aneurysm in the present patient.

In conclusion, the structural abnormality of the wall of the fistula conduit that is unrelated to atherosclerosis and mucoid degeneration may be one of the mechanisms underlying giant aneurysmal formation in patients with CAF.

\section{Disclosures}

Conflicts of interest: The authors state that they have no conflict of interest.

\section{References}

1. Angelini P. Normal and anomalous coronary arteries: definitions and classification. Am Heart J 1989; 117: 418-34.
2. Niwa R, Hasumi E, Fujiu K, et al. A Case of Multiple Coronary Artery-Left Ventricular Micro Fistulae Complicated With Hepatic Arteriovenous Fistulae. Int Heart J 2016; 57: 123-6.

3. Shiga Y, Tsuchiya Y, Yahiro E, et al. Left main coronary trunk connecting into right atrium with an aneurysmal coronary artery fistula. Int J Cardiol 2008; 123: e28-0.

4. Akashi H, Tayama E, Tayama K, et al. Rupture of an aneurysm resulting from a coronary artery fistula: a case report. Circ J 2003; 67: 551-3.

5. Gowda RM, Vasavada BC, Khan IA. Coronary artery fistulas: clinical and therapeutic considerations. Int J Cardiol 2006; 2013: 7-10.

6. Crawley PD, Mahlow WJ, Huntsinger DR, Afiniwala S, Wortham DC. Giant coronary artery aneurysms: review and update. Tex Heart Inst J 2014; 41: 603-8.

7. Suzuki H, Fujigaki Y, Mori M, et al. Giant coronary aneurysm in a patient with systemic lupus erythematosus. Intern Med 2009; 48: 1407-12.

8. Nakamura Y, Yutani C, Imakita M, et al. A huge coronary aneurysm resulting from a coronary artery-to-left ventricle fistula. Intern Med 1998; 37: 366-9.

9. Chamberlain MH, Henry R, Brann S, Angelini GD. Surgical management of a gigantic circumflex coronary artery aneurysm with fistulous connection to the coronary sinus. Eur J Cardiothorac Surg 2001; 20: 1255-7.

10. Iwasawa Y, Kitamura Y, Higuma K, Ono F, Imoto K, Kimura K. Cardiac tamponade due to rupture of coronary artery fistulas with a giant aneurysm containing a free floating ball thrombus: a case report. J Cardiol 2007; 50: 71-6.

11. Sugiura T, Saito S, Kihara S, Sato W, Kurosawa H. Giant coronary artery aneurysm associated with medial mucoid degeneration. Ann Thorac Surg 2009; 87: 933-4.

12. Mita N, Kaida S, Kagaya S, et al. Giant coronary artery aneurysm with coronary arteriovenous fistula draining into the coronary sinus. J Anesth 2011; 25: 749-52.

13. Hiraoka A, Kuinose M, Totsugawa T, Yoshitaka H. Giant coronary artery aneurysm arising from the sinus node artery with a fistula into the left atrium. Eur J Cardiothorac Surg 2013; 43: 646-8.

14. Morita H, Ozawa H, Yamazaki S, et al. A case of giant coronary artery aneurysm with fistulous connection to the pulmonary artery: a case report and review of the literature. Intern Med 2012; 51: 1361-6.

15. Frestad D, Helqvist S, Helvind M, Kofoed K. Giant aneurysm in a left coronary artery fistula: diagnostic cardiovascular imaging and treatment considerations. BMJ Case Rep 2013; 2013.

16. Surguladze G, Baduashvili A, Tamsen A. Case report: incidental finding of a giant cardiac mass. Methodist Debakey Cardiovasc J 2014; 10: 118-20.

17. Gundre NP, Mishra P, Aironi B, Vaideeswar P, Agrawal N. Giant aneurysm of the left atrial branch of the left circumflex artery with fistula. Ann Thorac Surg 2013; 96: 2240-3.

18. Isobe S, Hakuno D, Isoda S, Hayashi K, Adachi T. Right coronary artery-left ventricle fistula with giant coronary artery aneurysm. Eur Heart J Cardiovasc Imaging 2015; 16: 231.

19. Sakata N, Minematsu N, Morishige N, Tashiro T, Imanaga Y. Histopathologic Characteristics of a Coronary-pulmonary Artery Fistula with a Coronary Artery Aneurysm. Ann Vasc Dis 2011; 4: 43-6. 